\section{Spatiotemporal characterization of mercury isotope baselines and anthropogenic influences in lake sediment cores}

JU HYEON LEE ${ }^{1}$, SAE YUN KWON ${ }^{1}$, RUNSHENG YIN ${ }^{2}$ LAURA M. MOTTA ${ }^{1}$, AARON Y. KURZ ${ }^{3}$ AND SEUNG-IL $\mathrm{NAM}^{4}$

${ }^{1}$ Pohang University of Science and Technology

${ }^{2}$ Institute of Geochemistry, Chinese Academy of Sciences

${ }^{3}$ University of Michigan

${ }^{4}$ Korea Polar Research Institute

Presenting Author: jhl329@postech.ac.kr

A recent consensus from the literature suggests that increasing temporal trends in mercury isotope ratios in lake sediment cores from pre-industrial $(1510-1850)$ to present-day $(1990-2014)$ is a global phenomenon. While multiple hypotheses have been proposed regarding this widespread phenomenon, local to global scale changes including increased anthropogenic mercury emissions, climate change, and changes in atmospheric composition have made it difficult to decipher between sourceand processes-driven changes for mercury. Through compilation of mercury concentration $(\mathrm{THg})$ and mercury isotope ratios in twenty-two lake sediment cores collected from around the world, we explore reasons for the observed increase in mercury isotope ratio. In contrary to the consensus, we find that the increasing temporal trend in $\Delta^{199} \mathrm{Hg}$ is not a global phenomenon. Instead, a widespread phenomenon is the increasing $\delta^{202} \mathrm{Hg}$ together with mercury concentration in lake sediment cores from pre-industrial to present-day period. This can be explained by increased contribution of modern-day anthropogenic mercury emission sources, which have much higher $\delta^{202} \mathrm{Hg}(-0.9$ to $-0.3 \%$ ) compared to pre-industrial sediments $(-1.55 \pm 0.96 \%)$. The increasing trends in $\Delta^{199} \mathrm{Hg}$ were observed in fifteen lake sediment cores, which have low pre-industrial $\Delta^{199} \mathrm{Hg}$ $(-0.20 \pm 0.32 \%)$ compared to the sediment cores with near-zero to positive pre-industrial $\Delta^{199} \mathrm{Hg}(0.08 \pm 0.07 \%)$. No correlation was found between the magnitudes of $\delta^{202} \mathrm{Hg}\left(\mathrm{r}^{2}=0.09\right)$ and $\Delta^{199} \mathrm{Hg}$ $\left(r^{2}=0.20\right.$, both $\left.p>0.05\right)$ changes from pre-industrial to presentday with that of THg. This suggests that, rather than the extent of mercury input to the lake system, the magnitudes of $\delta^{202} \mathrm{Hg}$ and $\Delta^{199} \mathrm{Hg}$ changes are determined by the pre-industrial or baseline $\delta^{202} \mathrm{Hg}$ and $\Delta^{199} \mathrm{Hg}$ in the sediment cores. Our study suggests that the characterization of baseline mercury isotope ratios is critical for interpreting the observed temporal trends in sediment core mercury isotope ratios. Our study also suggests that sediment $\delta^{202} \mathrm{Hg}$ can be used as an important proxy for monitoring changes in anthropogenic mercury sources and for evaluating the effectiveness of the Minamata Convention on Mercury.

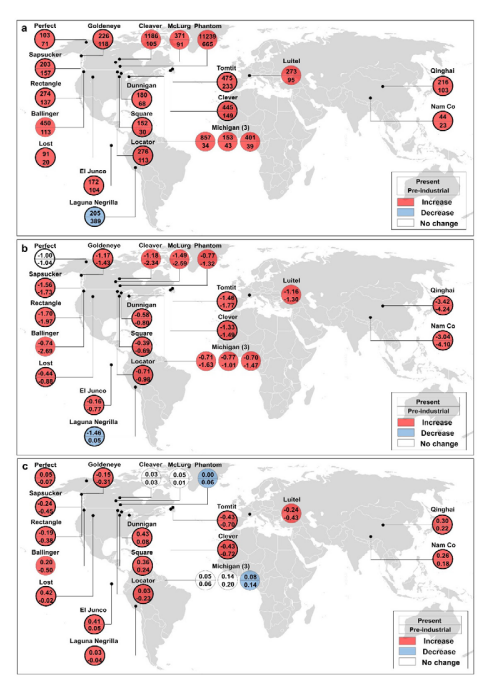

Figure 1. Spatiotemporal variations in a) $\mathrm{THg}$ concentration, b) $\delta^{202} \mathrm{Hg}$, and c) $\Delta^{190} \mathrm{Hg}$ from
the pre-industrial to present-day period in twenty-two lake sediment cores collected from the pre-industrial to present-day period in twenty-two lake sediment cores collected fron various regions of the world. The sediment cores presented i
sites and the remaining sediment cores indicate unremote sites 